\title{
Bilac em Lisboa
}

Antonio Dimas*

* Universidade de São Paulo. 
Ainda está por ser feito um trabalho minucioso sobre as viagens constantes de Bilac (1865-1918) à E uropa e a Portugal, em particular.

Em 1890, ao atravessar o Atlântico pela primeira vez, Bilac gozou da ventura de apertar a mão de Eça de Queirós, numa fria noite de dezembro de 1890. Comboiado por Eduardo Prado e por Domício da Gama, o poeta brasileiro foi conhecer de perto a pequena casa do bairro dos Campos Elísios, [...], onde Eça, casado e feliz, criara para gozo seu e gozo dos seus amigos um encanta do recanto de paz e trabalho no mei o da tumultuosa agitação da grande ci dade. ${ }^{1}$

Mais que simples recordação ou comovido necrológio, essa crônica, escrita dez anos de-pois da viagem, demarca o primeiro dos dois pontos fortes do contacto do poeta brasileiro com Portugal. Num primeiro momento, quando de suas primeiras idas à E uropa, seus interesses orien-tavam-no num sentido rigorosamente literário ou de confirmação e reafirmação de nossas fontes culturais. Mais tarde, já na segunda década deste século, tais viagens adquirem caráter político e cívico, dentro de um contexto ideológico inteiramente diferente, seja no plano dos interesses políticos internacionais, seja no plano individual do antigo poeta parnasiano.

Antes mesmo de apertar a mão de Eça, pela primeira e única vez, Bilac saíra em defesa de sua obra, no momento em que subia aos palcos cariocas uma adaptação de O Crime do Padre Amaro. ${ }^{2}$ Ainda mal instalado na Gazeta de Notíci as, o

Publicada em 19 de agosto de 1900, na Gazeta de Notícias do Rio de J aneiro, à guisa de necrológio, essa crônica de Bilac reaparece em pequena antologia que preparei, recentemente: Vossa Insolência, São Paulo, Companhia das Letras, 1996, p. 65-74. 
grande jornal de Ferreira Araújo, onde estreara poucos dias antes e onde ainda disputava espaço com o próprio E ça e com Machado de Assis, B ilac condenava a distorção do romance, concedida em nome de uma moral pública pre-sumida. Argumentando de forma técnica a favor da inviolabilidade da obra de arte e do respeito à sua lógica interna ou, de forma ética, contra sua utilização a serviço de uma causa qualquer, o cronista estreante insurgia-se contra sua legibilidade facilitada, sobretudo aquela que tivesse o intuito de proteger um padrão presumível de moral. Arvorando-se defensor da integridade da obra de arte, Bilac, em crônica de estréia, marca posição, exigindo, em meio à argumentação, que se respeitasse a atividade do intelectual e do artista, profissional como outro qualquer.

Ainda que longa, vale a pena transcrever a crônica, oportunamente publicada antes da primeira viagem:

“Não espere o Sr. Fabregas que fique impune o seu crime. Não confie nos aplausos do público, e muito menos nos elogios da crítica: o remorso, sombra implacável, pavoroso espectro, há de colar-se-Ihe aos passos e persegui-lo toda a vida.

Se, fazer de uma obra de arte, viva e vibrante, uma obra retórica de propaganda, é cousa que possa passar sem castigo, - então a justiça abalou definitivamente da terra e todos se julgarão com o direito de intercalar meia dúzia de tangos no $\mathrm{H}$ amleto.

E ça de Queirós não quis fazer propaganda anti-clerical no Padre A maro: o que ele quis fazer e o que fez, foi apanhar de surpresa um cantinho da sociedade portuguesa e passá-lo para três centenas de páginas fortes e eternas, com todos os seus ridículos e todas as suas hipocrisias. Que direito tinha o dramaturgo de acrescentar à obra do romancista um final absurdo, que destrói toda a lógica do livro, que adultera e desvia todos os seus intentos?

No romance, o padre Amaro continua a viver, vitorioso e feliz; no drama, um namorado de aldeia desfecha-Ihe um tiro de pistola, e, numa pífia tirada retórica, berra à platéia comovida que acaba de livrar a sociedade de um bandido. Quem faz isso, é capaz de transplantar para o palco brasileiro o Otelo, acrescentando-Ihe um epílogo em que o mouro, em vez de morrer, faça um discurso veemente, lastimando que não haja lei de divórcio para que os maridos, supondo-se enganados, tenham além do tuez-la, outro meio de castigar as adúlteras.

O u o dramaturgo não concordou com o final que o romancista deu à sua obra, ou receou que a platéia se escandalizasse demais com as escabrosidades da peça e quis moderar o escândalo; no primeiro caso, o dramaturgo só tinha uma cousa a fazer: conceber uma peça original, desenvolvê-la à vontade, dar-Ihe o final que mais o encantasse, sem cometer a imprudência

2 Ao adaptar de forma moralista o romance de Eça, Augusto Fabregas não imaginava, talvez, o alarido que ia causar. À reação encabeçada por Artur Azevedo, crítico teatral de enorme prestígio naquele momento, associou-se a do cronista Bilac, que consideravar Artur como seu padrinho profissional. Ver, neste sentido, necrológio que Ihe dedica Bilac, em Vossa Insolência, p. 105-111.

O episódio da adaptação teatral de O Crime do Padre Amaro está relatado por Arnaldo Faro em Eça e o Brasil. São Paulo, Cia. Editora Nacional-E DUSP, 1977, p. 200-204. 
ridí-cula de emendar quem se chama E ça de Queirós; no segundo caso não devia fazer nada: a audá-cia não tem meio termo - ou não se dá o primeiro passo ou dão-se todos.

As obras de arte como o Crime do Padre A maro são sagradas: o adaptador do belo romance português incorreu no mesmo crime sem perdão do conhecido poeta brasileiro, que para uso das escolas modificou inteiramente os Lusíadas, por achar pouco compreensível o estilo de Camões.

O Crime do Padre Amaro custou a Eça de Queirós longos anos de trabalho literário, que é o mais nobre, o mais difícil, o mais fatigante, o mais sagrado de todos os trabalhos: não espere o Sr. Fabregas que E ça de Queirós o absolva do seu crime.

Não há artista nenhum que perdoe esse atentado: quando se consegue, com o cérebro fatigado, com todos os nervos dolorosamente irritados, ver acabada a obra em que se pôs todo o ta-lento, toda a mocidade, toda a saúde e toda a alma, não se perdoa que ninguém faça dessa obra uma peça de escândalo, fútil, adulterada, torta, para dar enchentes a um teatro.

Permita-me o Sr. Fabregas esta rude franqueza de quem respeita, acima de tudo, o seu métier: eu não posso achar agradável que ponham roupas de arlequim nos meus ídolos e que, pa-ra fazer uma plantação de couves, ponham abaixo todas as rosas do meu jardim." (G azeta de Notícias. Rio de J aneiro, 28 abr.1890).

Essa crônica pode ter servido, de forma voluntária ou não, como passaporte perfeito para o encontro de Bilac com Eça em Neuilly. Os redondos vinte anos de idade que separavam o ro-mancista famoso do poeta estreante, colocavam o brasileiro no patamar de admirador inte-lectual, sobretudo se nos lembrarmos de que sua visita era intermediada pela mão generosa de E duardo Prado, amigo íntimo de E ça e fiador do encontro, e de Domício da G ama, conviva da família deste a temporada dos Queirós na I nglaterra. Se duas décadas exatas punham E ça e Bilac em distância etária razoável, aproximava-os, no entanto, o humor, ainda juvenil do brasileiro, mais maduro, no caso do português. ${ }^{3}$

Conseqüência literária desse encontro único documentou-a Heitor Lyra, que transcreve, em O Brasil na vida de Eça de Queiroz, versão galhofeira da história de Inês de Castro, escrita a oito mãos pelo poeta brasileiro, por Eça, sua esposa e sua cunhada, nos serões de N euilly. No entanto, preocupado apenas com o respeito à integridade do episódio e com a autoria precisa das partes, o historiador passa ao lado dessa brincadeira dessacralizante e pouca atenção dá àqueles versos de extensão variada e dinâmica, permeados de anacronismos, de onomatopéias e de situações absolutamente prosaicas e vulgares. Como, por exemplo, aquela em que se observa $D$. I nês cosendo meias, sentada num barquinho de pau sobre o Mondego, enquanto espera por um esbaforido D. Pedro, que, na pressa de encon-

A lém do livro de $\mathrm{H}$ eitor Lyra, vali-me também, no caso das relações entre E ça e B ilac, da biografia de E duardo Prado, escrita por Cândido Motta Filho: A vida de Eduardo Prado, Rio de J aneiro, J . Olympio, 1967. 
trar sua amada, derreou sei s corcéis, engoliu os espaços. / Tel efonou, / Tel egrafou, / correu, suou, / Voou!... ( p. 292). O ponto alto da troça, no entanto, ocorre durante um banquete permissivo no qual se farta $D$. Pedro, excitado diante de um cortejo de pratos preparados pelas mãos ingentes / da que depois de morta foi Rainha. Não bastassem o carinho conjugal ea profusão das azeitonas, das batatinhas bem assadas e louras, das saladas de alface e de cenoura, da açorda de alho, do leitãozinho assado com perícia, da divina cabidela, da lampreia guisada, do presunto sublime de Lamego, dos doces e dos pastéis, D. Pedro se permite ainda misturar carne com peixe, bem como avançar em delícias futuras: Depois o I nfante, todo recostado, / Saboreou com um sorri so farto e aberto, / Café que ainda não fora descoberto / E charuto que depois foi inventado... ${ }^{4}$

A pesar do caráter brincal hão desses versos, que contraria a pompa camoniana e rebaixa um dos mitos portugueses mais caros, a memória geral do encontro, mais tarde recuperado pela pena de Bilac, quando da morte de Eça, em 1900, salienta menos a irreverência do escritor por-tuguês do que sua maturidade burguesa. Para Bilac, aquele Eça de 1890, que já ficara conhecido como fiel e aspérrimo discípulo do realismo, como dele disse Machado, em crítica famosa, aque-le E ça mostrava-se contido, por fora e por dentro. Por fora, aparentava sóbria e fina elegância de gentil-homem, sem uma nota espalhafatosa no vestuário, sem uma afetação no dizer. Naquela década distante e rodeado pela família num bairro calmo da capital francesa, continua B ilac, o romancista que castigara a choldra lusitana já não era /.../ o leão da moda, célebre pelas suas gravatas e o "blagueur" impenitente, célebre pelos seus paradoxos. (Gazeta de Notícias (RJ ), 19 ago. 1900).

Em 1890, afirma o visitante brasileiro, já o amor e a felicidade doméstica haviam trans-formado o espírito do prodigioso escritor. Diante de si, Bilac tinha agora um intelectual mais ponderado e mais preocupado com a forma, com a reversão à primitiva pureza dos clássicos, com o culto fanático do estilo, enjoado dos barbarismos deliberados e decidido a transformar seu estilo em ouro puro, trabalhado como uma custódia de Benvenuto Cellini. Desse encontro, o poeta brasileiro, que acabara de alcançar repercussão nacional com seus poemas parnasianos, publicados em 1888, retivera uma visão rigorosa e minuciosamente lingüística e formal, dentro da qual não falta nem mesmo a imagética das pedras preciosas ou da miúda e brilhante tecelagem chinesa. Lembrando-se de que, pouco antes de 1890, a Gazeta de Notíci as publicara a novela O defunto de Eça, Bilac comenta:

4 O encontro de Bilac com Eça, em Paris, está relatado por Heitor Lyra em O Brasil na vida de Eça de Queiroz, pref. de Maria d'E ça de Queiroz, Lisboa, Livros do Brasil, 1965, p. 283-301 e 312-315. 
"Ali, naquela Bíblia da moderna língua portuguesa, quando um verbo chama o substantivo, e se amalgama com ele na estrutura da oração, - logo um adjetivo, o próprio, o verdadeiro, o único, aparece a ocupar o seu lugar. Tudo aquilo é firme, é miúdo, como a trama de uma seda de Macau.

Para escrever assim, é preciso pensar, sofrer, suar e gemer sobre o papel, numa agonia ino-minável; é preciso matar os olhos e espírito no labor acurado, como um lapidário os mata no desbasta-mento das sessenta e seis faces de um brilhante." (Gazeta de Notícias (RJ ), 19 ago. 1900).

E , como se ainda fosse necessário enfatizar o esmero de Eça no tratamento estilístico da língua portuguesa, Bilac recorre à figura do parnasiano francês Heredia, dele aproveitando verso que exalta a atitude de Frei J uan de Segovia que, agonizante, ainda cinzelava em ouro um ostensório. No final da crônica, o frei espanhol entrava em cena para acolitar e reforçar a evocação a B enevuto Cellini, o escultor, linhas acima.

Em suma, o Eça que Bilac tivera o prazer de encontrar uma única vez na vida, justamente num espaço de desterro intelectual prezadísimo de ambos, não era o romancista que, anos antes, enrubescera a burguesia portuguesa, mas o Eça que investia pesado na defesa do patrimônio lin-güístico herdado, como instrumento possível de identidade nacional.

Anos mais tarde, no ano de 1904, Bilac toca de novo em Portugal, em sua segunda viagem à E uropa.

Desta vez, além de uma visita à estátua de $E$ ça, no L argo do B arão de Quintela, o cronista detém-se nas recentes reformas urbanas de Lisboa, que a adornaram de ruas largas e admi rávei s, que se estendem à bei ra do Tejo, fa cilitando as comuni cações, e rejuvenescendo a vel ha urbe pombalina. (Gazeta de Notícias (RJ ), 08 jun. 1904). E mpolgado com as reformas urbanas do R io de J aneiro, que, sob o comando de Pereira Passos e de Paulo de Frontin, mal haviam começado, Bilac toma o novo traçado lisboeta como sinônimo necessário de progresso, tese que virá defen-der, durante anos, através das páginas da Gazeta de Notícias, em sua campanha pela reforma da cidade do $\mathrm{R}$ io. De seu ponto de vista, o novo desenho da capital portuguesa decretaria, por força, a morte do provincianismo local e, no fundo, poderia funcionar como estímulo matricial às refor-mas em andamento no Rio de J aneiro.

Se o traço novo de Lisboa permite-Ihe expor em público sua confiança na correlação necessária entre cosmopolitismo e reurbanização, uma de suas obsessões fora do plano literário, é diante da estátua de E ça, no entanto, desaparecido quatro anos antes, que o cronista vai revelar o que mais o atrai no autor de Os Maias: sua ironia. 
É bem verdade que o grosso da crônica detém-se na construção do espaço e do tempo, dados circunstanciais que preparam e acentuam a presença isolada do sólido bloco de granito no qual estão representados a Verdade e o escritor. Num lugar meio afastad o e silencioso, benefi-ciado por movi mento comercial insignificante, o cronista brasileiro admira a estátua, plantada contra um casario baixo, escuro e muito mal iluminado por um luar desmaiado e suave, que acentuava com o seu clarão mortiço a velhice e a tristeza das cousas. (Gazeta de Notícias (RJ ) 12 jun. 1904). A o longe, debruando o conjunto escultórico, as luzes da cidade moderna fundem-se aos sons urbanos como que num esforço para acentuar, por contraste, a calmaria do Largo do B arão de Quintela.

A descrição paciente do bloco em que se entrelaçam o escritor e a Verdade não tem outro objetivo senão o de preparar o leitor para a entrada dos parágrafos finais da crônica. Por meio dessa estratégia estrutural, iniciada com uma interrogativa retórica, o cronista estende-se sobre os efeitos da ironia, com o intuito tortuoso de sugerir identidade de comportamento que o ligue ao escritor português. E se a sugestão de identidade pode parecer presunçosa, que reste, ao menos, a de modelo.

“Que foi a ironia de Eça de Queirós, senão um disfarçado desespero de todo o artista diante do mistério impenetrável da existência? O homem, afinal, é apenas uma criança adulta... E nós todos somos como as crianças e como os animais, que dilaceram e magoam o que não podem compreender...

De certos escritores, é hábito dizer que perdem o coração à medida que apuram o cérebro. Realmente, nada parece a princípio mais cruel, mais privado de bondade, mais despido de "humanidade" do que o ofício desses pensadores de eleição, que se comprazem em analisar misérias e ridículos, pondo a nu todas as chagas morais dos seus semelhantes, remexendo todos os seus sofrimentos e insultando a sua fraqueza ou rindo da sua miséria...

Quem mais sofre, porém, nessas duras análises, é sempre o analista. O sorriso cético e frio que lhe enruga os cantos da boca, é apenas o disfarce da sua agonia. O desejo de alcançar a verdade e a perfeição é a sua fortuna e o seu castigo." (G azeta de Notícias (RJ) 12 jun. 1904).

Entre os biógrafos de Bilac, R aymundo Magalhães J r. é aquele que menos se comprome-te, ainda que seu livro padeça do mesmo defeito visceral que quase inutiliza suas outras biogra-fias: a informação documental duvidosa, que jamais permite sua verificação e sua comprovação, dado o péssimo hábito de sonegar a precisão das fontes. Com cuidado, com muito cuidado, no entanto, é possível abastecer-se de dados profissionais, pelo menos como ponto de partida a ser, mais tarde, conferido. Desta segunda viagem à E uropa, R aymundo $M$ agalhães destaca 
apenas, no que se refere à escala em L isboa, o interesse do cronista em negociar a publicação de seu terceiro livro de prosa, Crítica e Fantasia, cuja primeira edição acabou saindo pela Livraria Clássica E di-tora de A. M. Teixeira, ainda em $1904 .^{5}$ Antes, em prosa e de autoria individual, haviam saído Crônicas e Novelas, em 1894, e Contos para Velhos, em 1897, escondidos sob o pseudônimo de Bob. Os interesses do cronista, nesse momento, ainda se limitavam à sua afirmação e à sua con-solidação, no campo literário e intelectual.

Mais de dez anos depois, em plena Primeira Grande Guerra, Bilac ainda volta ao continente europeu, duas vezes: em 1914 e 1916. Nesta derradeira viagem, recolheria ele, de forma apoteótica, os resultados de seus freqüentes contactos anteriores com a inteligência portu-guesa. E m clima inteiramente diverso, no qual ainda se respirava a excitação residual da im-plantação republicana de 1910 e já se angustiava com a recente ad esão de Portugal à guerra, ao lado do Aliados e em nome dos valores latinos, homenageava-se mais o ideólogo do nacionalis-mo brasileiro que o poeta parnasiano das Panóplias, Via-Lactea e Sarças de fogo, seus livros de 1888.

Esmiuçar um pouco o conjunto das reverências que lhe foram prestadas pela revista Atlântida, entre os dias 30 de março e 3 de abril de 1916, ajuda talvez a compreender melhor os objetivos da homenagem, bem como o contexto pessoal e geral que se criara em torno. J á desde o ano anterior, quando Bilac dera início à sua pregação cívica e militar, a revista Atlânti da dava cobertura às suas atividades de propagandista, logo em seu segundo número, de 15 de dezembro de 1915. Em números subseqüentes, como o de fevereiro ou de outubro de 1916, há inserções ou artigos a respeito da campanha pelo Serviço Militar Obrigatório, que já corria solta no sul do B rasil. O número 12 da revista, de outubro de 1915, traz até mesmo fotografias de Bilac em plena tarefa de conscientização cívica.

É nesse contexto, pois, de reforço do militarismo, estimulado ainda pela crença, generalizada na Europa, de que a guerra em andamento representava a resistência do espírito latino contra a barbárie germânica, que Bilac é recebido em Lisboa. Como autêntico porta-voz de uma latinidade americana, bastião último capaz de enfrentar a insanidade germânica que tanto ameaçava a espiritualidade latina encarnada e defendida pela França.

Entre as tantas entrevistas concedidas a periódicos lisboetas, assim que desembarca na capital portuguesa, proveniente de Paris, destaquem-se trechos de uma delas, concedida ao jornal A Capital, em 26 de março de 1916, nos quais ficam patentes sua latinofilia e a defesa da nacio-nalidade brasileira, sobretudo a dos nossos estados meridionais, posta em questão por causa de sua farta população 
de imigrantes de origem germânica. Exatamente aqueles E stados, cujos do-mínios seriam por ele visitados, em breve, em campanha que cobriu o R io G rande do Sul, Paraná e São Paulo, entre outubro e novembro de 1916.

$\mathrm{Na}$ abertura da entrevista, a repórter Virgínia Quaresma, confessando-se cativa de sua poesia, conduz a conversa, de preferência, no rumo de temas políticos e concede, apenas no final, uma brecha para a literatura. Assim, diante da posição brasileira perante o conflito em curso, Bi-lac responde:

“O Brasil é francófilo, absolutamente francófilo. É a sua raça, a sua cultura, é a sua alma, enfim, que o levam a abraçar, neste grande momento histórico e através a imensidade do Atlântico, os destinos sagrados da França..."

À pergunta sobre uma suposta germanização do Estados do B rasil meridional, a negação é taxativa:

“Não é verdade, não. E fetivamente, a colônia alemã é importante nesses E stados e um fator do seu desenvolvimento econômico, mas aí, como em todo o país, vive [sic] intacta a consciência, o sentimento nacional. Não, pode desassombradamente declarar, os Estados a que se refere, felizmente, não estão germanizados."

E o Sr. acha que o Brasil deveria adotar uma política de povoamento baseada na seleção de raças?

“Não, responde rápido o entrevistado. Entendo que devemos receber colonos de todas as raças, de todos os povos, mantendo assim as nossas tradições de liberalidade. Mas entendo também que o problema do povoamento se não impõe agora como uma das questões nacionais mais urgentes, mais inadiáveis. A nossa população é de vinte e cinco milhões e, por enquanto, essa chega-nos."

Então, retruca a jornalista, o que é que de urgente se impõe nesse momento?

“U ma campanha, uma intensa propaganda para desenvolver o espírito de coesão nacional, retorna Bilac. Eu sei muito bem, estou intimamente convencido, que em cada brasileiro se encontra um ardente patriota, mas acho imperioso que se trabalhe para conseguir a unificação, a comunhão do ideal de nacionalidade."

E é exatamente para essa pregação que se prepara o visitante, que promete:

“L ogo que chegar ao B rasil, [ fazer conferências em campanha] será o meu primeiro cuidado, a minha primeira atenção. Após 15 dias de repouso no Rio, seguirei para os 
Estados de Santa Catarina, do Paraná, do R io Grande do Sul, a fim de dar início à minha missão."

M issão em que se incluem, necessariamente, ajunta ele, a difusão do ensino primário, a expansão do ensino profissionalizante e o serviço militar obrigatório, cuja função, por mais para-doxal que possa parecer, é exatamente a de evitar qualquer tipo de conflito, segundo seu racio-cínio:

“O ensino militar obrigatório impõe-se sob todos os aspectos e as suas conseqüências nunca pode-rão ser senão excelentes. A Argentina há cerca de vinte e cinco anos que o adotou e, desde então, na sua vida não se registra uma revolução, a mais pequena sublevação. Compreende-se que, tendo recebido igualmente todos os cidadãos o ensino militar, se receiem e se respeitem mutuamente."

Armado dessa argumentação pedagógico-castrense, Bilac entra numa Lisboa que, cerca de vinte dias antes, havia declarado guerra ao adversário alemão e que, portanto, estava ávida pa-ra ser confirmada, legitimada e reconhecida em sua beligerância, sobretudo se esse reconheci-mento viesse de um intelectual, de um poeta da mesma língua e da mesma extração cultural. A fusão do político e do ideológico com o poético não poderia ter ocorrido em momento mais que adequado. No congraçamento dessas esferas, intercambiavam-se prestígios específicos, em bene-fício de ambos os lados, como bem se pode avaliar a partir desta nota da redação da revista Atlântida:

“Durante a sua recente permanência em Lisboa, Olavo Bilac foi alvo das mais significativas homenagens de admiração e carinho por parte de todas as classes sociais. $O$ chefe do E stado quis ter a honra de o sentar à sua mesa, oferecendo-Ihe um jantar íntimo em que foram igualmente convivas algumas ilus-tres personalidades literárias e o diretor da Atlântida, dr. J oão de Barros. Domingo, 26 de março, reali-zou-se em honra do presidente da R epública uma grandiosa manifestação popular, a propósito da entrada de Portugal na guerra européia. O cortejo, composto de muitos milhares de pessoas, foi desfilar perante o edifício da câmara municipal, em cuja varanda estava o dr. Bernardino Machado, os membros do governo e os ministros das nações aliadas. Pouco antes, passara em frente do Avenida Palace e como a multidão descortinasse a uma das janelas Olavo Bilac, que presenciava o desfile, ergueram-se de todas as bocas, frementes de entusiasmo, vivas calorosos ao B rasil, à R epública irmã e ao seu grande poeta. Foram alguns minutos de inolvidável comoção. As salvas de palmas estrugiram, os chapéus e os lenços agitaram-se no ar, todos pararam voltados para Bilac surpreendido com aquela admirável demonstração de afeto à sua gloriosa pátria. O eminente lírico agradeceu profundamente sensibilizado, erguendo um Viva a Portugal. 
No dia 28, três do jornais noturnos de Lisboa, A Capital, O Século e A Opinião, inseriam interessantes entrevistas com O lavo B ilac acerca da atitude do $B$ rasil em face da presente situação internacional." (Atlântida (L isboa) , no 6, 15abr. 1916).

Afora o Presidente da R epública, quem mais cercou, afagou, aplaudiu, incitou e endossou aquele homem de prestígio social e intelectual, solidamente plantado em seu país?

Quem mais adulou aquele poeta?, que ajudara a fundar a A cademia Brasileira de Letras, em 1896; que assumira o lugar do cronista Machado na Gazeta de Notícias, em 1897; que, na qualidade de jornalista, fizera parte da comitiva do P residente Campos Sales em sua visita à A r-gentina, em 1900; que fora apontado delegado brasileiro pela Alliance Latine de Paris, junto às festas de Renan, em 1903; que fora designado pelo B arão do R io Branco, em 1906, para secre-tário da 3a Conferência Pan-A mericana, realizada no Rio de J aneiro, durante a qual secretariou J oaquim Nabuco; que, no R io, fora homenageado por banquete de admiradores, em 1907, quan-do suas Poesias iam completar vinte anos de edição; que, no ano seguinte, fora convidado pelo prefeito do R io de J aneiro, Sousa Aguiar, para orador oficial da inauguração do Teatro Munici-pal; que fora nomeado delegado brasileiro junto à 4a Conferência Pan-Americana, reunida em Buenos Aires, em 1910; que havia sido escolhido, de modo consagrador, "P ríncipe dos Poetas B rasileiros", em concurso promovido pela Fon-Fon, em 1913.

Quem mais cercou e festejou aquele escritor reconhecido que, até aquele momento, era autor de diversos livros individuais ou em colaboração, como Poesias (1888), Crônicas e Nove-las (1894), Contos para Velhos (1897, sob o pseudônimo de B ob), Pimentões ( 1897, com Gui-marães Passos), A Terra Fluminense (1898, com Coelho N eto), Li ra Acaciana (1900, com Al-berto de Oliveira e Pedro Tavares J r.), Livro de Leitura (1901, com Manuel Bonfim), Crítica e Fantasia (1904), Contos Pátrios (1904, com Coelho Neto), Guide des États Unis du Brésil (1904, com Guimarães Passos e Souza B andeira), Livro de Composição (1904, com Manuel B omfim), Tratado de Versificação (1904, com Guimarãs Passos), Poesias I nfantis (1904), Tea-tro Infantil (1905, com Coelho Neto), Conferências Literárias (1906), Através do Brasil (1910, com Manuel Bonfim), A Pátria Brasileira (1911, com Coelho $\mathrm{Neto}$ ), para mencionar apenas uns poucos.

Que motivações recíprocas poderiam estar em curso durante aqueles dias, em Lisboa, quando Bilac foi recebido, de forma oficial, pela Academia de Ciências, foi homenageado pela Revista Atlântida e pronunciou conferência em pleno Teatro da R epública? Que motivos provo-cavam tantas comemorações, enfim?

Pelo visto, o reforço da lusitanidade e da latinidade, através da defesa do idioma, miolo, por sua vez, dos nacionalismos a galope, nos dois países. 
A presença significativa de alguns nomes do círculo político, governamental e intelectual luso-brasileiro, bem como a leitura atenta dos vários discursos pronunciados durante as soleni-dades permitem essa conclusão, sem prejuízo de outras.

Depois de ouvir os discursos de recepção na Academia de Ciências de Lisboa, onde foi recebido na noite de 30 de março de 1916, a resposta de Bilac pautase pela defesa do tradicio-nalismo e do nacionalismo: Sempre fui um tradicionali sta, sem ser um retrógrado, admite ele, acrescentando: E ste meu tradicionalismo não é incompatível com o meu nacionalismo. (Atlân-tida, no 6, 15 abr. 1916. p. 571) ${ }^{6}$

Avalista mor desse comportamento em que Bilac não enxerga discrepância é a figura avoenga de J osé B onifácio de Andrade e Silva, que, segundo sua lembrança expressa no discur-so, partira daquela mesma Casa de letras e de ciências em 1819 para, poucos anos depois, tornar-se o Patriarca da Independência brasileira, sem que isso Ihe arranhasse o prestígio pessoal, polí-tico e científico.

$\mathrm{Na}$ presença de figuras proeminentes como Cândido de Figueiredo, J úlio Dantas, J oão de Barros, Fidelino de Figueiredo, Edgar Prestage e J oão Lúcio de Azevedo, Bilac reitera seu nacio-nalismo aceso, através de forte metaforização botânica, que não admite plantas inferiores, de aparência parasitária, errática ou aérea como as algas, as aeróbias e as epífitas. No âmbito de sua imagética botânica, cabem apenas as grandes e belas árvores, de longas e profundas raízes, que se aferram ao mais remoto e secreto seio da terra, no âmago do solo consagrado pelos tempos, regado pelo suor, fecundado pelas lágrimas, lavrado pelo sacrifício de muitas gerações de trabalhadores. (Atlântida, no 6, 15 abr. 1916. p. 573). Logo depois desta afirmação, ao empare-Ihar a Academia com bosques sagrados (id. p. 573), o homenageado prolonga a metáfora, recua aos tempos helênicos e mais uma vez puxa à memória o século 18 , como o fizera quando men-cionara a formação intelectual de J osé Bonifácio, homem do Iluminismo e elemento de ligação entre Portugal e B rasil, na medida em que esse nosso pró-homem não renegava a metrópole amamentadora do seu espírito. (Atlântida, no 6, 15 abr. 1916, p. 572). Com essas lembranças sussurrando no ouvinte, arma-se o quadro preferencial em que se aliam razão e sentimento, ciên-cia e poesia, E uropa e A mérica, G récia clássica e Iluminismo, século 18 brasileiro e vontade de emancipação política, reverência e independência. Nada mau para quem se via recebido como cultor de poesia, da língua e da história.

O banquete que Ihe ofereceu a Atlântida, na noite seguinte, foi o ápice.

6 Mais tarde, esse discurso reaparece publicado em Últimas conferências e discursos, obra póstuma, Rio de J aneiro, Francisco Alves, 1924. 
Na notícia que a revista traz, em mead os de abril, é de se notar que um busto da República presidia a sessão de 31 de março, como que injetando autoridade, prestígio nacional e institucional à cerimônia.

R odeado por nomes como Henrique L opes de M endonça, presidente da Academia de Ciências de Lisboa e daquela sessão; Fernandes Costa, M inistro do Fomento; Major Pinto Maia, secretário geral da Presidência da R epública; M anuel Monteiro, presidente da Câmara dos Deputados e Pedro M artins, M inistro da Instrução, Bilac ouviu prolongados discursos nos quais a tônica eram:

- o perigo que rondava a civilização contemporânea;

- o embate entre o espíri to nórdico, a um tempo nebuloso e duro, e o espíri to meridio-nal, luminoso e sutil (p. 575);

- a superioridade latina sobre a barbárie germânica;

- a pujança da civilização greco-latina;

- a imortalidade da nossa raça (p. 576);

- a estreita vinculação familiar ou fraterna entre Portugal e Brasil;

- o desdobramento da cultura lusitana do outro lado do Atlântico;

- a garantia de sua continuidade americana.

A esses tópicos, ressaltados aqui e ali, em meio aos nove discursos, Bilac responde de forma extensa, fincando posição que atenua bastante seu passado de poeta parnasiano e remobiliando esse espaço disponível com a defesa da língua como veículo eterno e imutável de ex-pressão.

Depois de percorrer rapidamente o curso da literatura portuguesa, desde os trovadores até o naturalismo de seu adorado E ça e o lirismo de J oão de Deus ou de G uerra J unqueiro, curso do qual afasta, matreiro, o parnasianismo, o conferencista da noite insiste no enquadramento da sintaxe como fenômeno imutável da língua, mesmo que, eventualmente, ela se adorne como as mulheres, que vestidas com pureza e simplicidadade, são enlevo para todos os ol hos artistas e para todas as almas finas... (Atlântida, no 6, 15 abr. 1916, p. 595).

No seu modo de entender a veiculação da língua, a defesa intransigente da intimidade sintática do idioma evitaria sobressaltos mais amplos no momento em que estivessem em jogo a existência e a li berdade, a honra eo futuro de todas as nacionalidades, disseminadas pela Europa e pela América, nascidas da antiga civilização do Mediterrâneo, irmanadas pela arte e pela filosofia, e ligadas pela afinidade dos idi omas brota dos do tronco do Láci o... (A tlântida, no 6, 15 abr. 1916, p. 595).

Daí, por exemplo, afirmar de modo surpreendente para quem cultivara o parnasiansimo com tanta paixão: Nesta época, a arte pela arte seria uma monstruosidade moral. (Atlântida, no 6, 15 abr. 1916, p. 592).

Surpreendente, em termos, essa rejeição, no entanto. Surpreendente para quem não sabia que esse caminho vinha sendo preparado há algum tempo. Um ano, pelo menos, antes desse dis-curso, o "Parecer" que recomendava a candida- 
tura de Olavo Bilac à Academia de Ciências de Lisboa já carregava nas tintas da defesa nacional através do idioma. ${ }^{7}$ Segundo a argumentação de quem o assinava, impunha-se o acolhimento a um candidato que tanto crescera diante de todos como defensor do idioma português e cujo extremoso carinho filial pelo patrimônio i di omático, legado pelos pi onei ros da Europa à terra maravi Ihosa deSanta Cruz, já ficara mais que de-monstrado. Através de B ilac, reza o "Parecer", estaria garantida a sobrevivência da língua e, por extensão, a de Camões, poeta máximo da identidade lusitana. M enos que ao poeta brasileiro, por-tanto, que não precisava de quem o defendesse, defendia-se ao defensor da língua.

Quem argumenta nesse sentido é quem assina o "Parecer": Henrique Lopes de Mendonça, naquele momento o presidente da Academia de Ciências de Lisboa. Sua assinatura, persuasiva em si pelo cargo que ocupava, era ainda rodeada de outros nomes tão relevantes e consolidados quanto o seu.

Um alargamento explicativo do significado institucional e político desses nomes, que, in-felizmente não cabe nos limites desta introdução, talvez ressaltasse melhor a relevância política e ideológica destas relações de Bilac com o poder português daquele então. Porque, afinal de con-tas, não se pode tomar como desinteressada e inocente uma recomendação acolitada por nomes como o de Teófilo B raga, A. Brancaamp F reyre, J úlio Dantas e Cândido de Figueiredo.

Aquela rejeição ao dogma parnasiano da "arte pela arte" não fora senão um momento propício para B ilac reafirmar sua combatividade nacionalista, agora ancorada sobre a defesa da integridade da língua que nos é comum. Defesa que se encaixava como luva nos interesses ideológicos dos dois lados do Atlântico português, quando - temia-se - o fantasma bosche amea-çava a sobrevivência latina, fora das fronteiras portuguesas e dentro das brasileiras. Tanto que B ilac embarca para o $\mathrm{R}$ io $\mathrm{G}$ rande do Sul, meses depois de encerrad o esse circuito europeu, com o objetivo explícito de convocar os gaúchos para a construção de uma imensa e gloriosa mura-Iha circular, guardando o sagrado páramo, em que circula a nossa história. ${ }^{8}$

Com a viagem ao extremo sul do Brasil, entre outubro e novembro de 1916, fechava-se o círculo atlântico que, ao norte, começara com as festas lisboetas, patrocinadas pela revista Atlântida, cujo ato de fundação apostava em falar a mesma língua, representar a mesma lusitana esti rpe, ter uma fórmula comum de civilização. ${ }^{9}$ Poucos anos depois, com a eclosão da Semana de Arte Moderna e seus desdobramentos, verifica-se que a aposta não deu certo.

\footnotetext{
O manuscrito do "Parecer" que recomenda Olavo B ilac à Academia de Ciências de L isboa, datado de 03 de junho de 1915, encontrei-o na pasta referente ao poeta, nos arquivos da Academia de Lisboa, em pesquisa financiada, tempos atrás, pela Fundação Gulbenkian e pela FAPESP, instituições às quais devo meus agradecimentos. Também os jornais e as revistas portuguesas consultadas resultam dessa pesquisa.

8 O. Bilac, Últimas conferências e discursos, R io deJ aneiro, Livraria Francisco Alves, 1927, p. 183. "Ao Rio G rande do Sul”.
} 
Aliás, como demonstra ensaio recente, nesse mesmo momento já se punha em dúvida essa fraternidade transatlântica esteada na língua. Pelo menos é o que se entrevê nos artigos esparsos da Revista do Brasil, periódico criado em defesa de uma nacionalidade que emergia com força, de novo, às margens do I piranga. ${ }^{10}$

São Paulo, abril de 1999.

9 Estas palavras constam da nota de apresentação da revista, fundada por J oão de Barros e J oão do R io. Mais tarde, J oão de Barros recolheu-as em Presença do Brasil. Páginas escolhidas (1912-1946), Pref. de Ribeiro Couto, LisboaRio: Livros do Brasil-Livros de Portugal, s.d., p. 73.

10 Refiro-me ao ensaio de Tânia Regina de Luca: A Revista do Brasil: Um diagnóstico para uma (N) ação, São Paulo, Edi-tora da UNESP, 1999.

Por outro lado, uma série substancial de documentos sobre nacionalismo lingüístico foi recolhida por E dite Pimentel Pinto em antologia bem abrangente: O português do Brasil. Textos críticos e teóricos, Rio de J aneiro: LTC, São Paulo: EDUSP, 1978. 2. v. 
